\title{
Whole grain health claims in the USA and other efforts to increase whole-grain consumption*
}

\author{
Len Marquart ${ }^{1 \dagger}$, Kathryn L. Wiemer ${ }^{2}$, Julie M. Jones ${ }^{3}$ and Brenda Jacob ${ }^{4}$ \\ ${ }^{1}$ Department of Food Science and Nutrition, University of Minnesota, Eckles Avenue, St Paul, Minnesota 55108, USA \\ ${ }^{2}$ Bell Institute of Health and Nutrition, General Mills Inc., Minneapolis, Minnesota 55427, USA \\ ${ }^{3}$ College of St Catherine, 2004 Randolph Avenue, St Paul, Minnesota 55105, USA \\ ${ }^{4}$ Quality and Regulatory Regulations, General Mills Inc., Minneapolis, Minnesota 55427, USA
}

\begin{abstract}
In response to the 1990 Nutrition Labeling and Education Act, the Food and Drug Administration approved seven health claims that addressed the relationship between broad food categories and risk of certain chronic diseases. These claims are based on scientific consensus that includes epidemiological, animal and clinical research. The Food and Drug Administration also established a process to petition for new health claims that address substance-disease relationships supported by adequate scientific and specific regulatory requirements. The whole grain-cancer and heart disease authoritative statement health claim approved in July 1999 followed a completely different process mandated by the Food and Drug Administration Modernization Act of 1997. It is based on an authoritative statement made by a government body that represents scientific consensus and is supported by other scientific agencies and organizations. The scientific basis for the claim published in Diet and Health reflects a comprehensive and deliberative review of epidemiological, animal and human studies by the National Academy of Sciences Committee on Diet and Health. Health claims used on wholegrain products can attract the attention of health-conscious consumers and are important tools in communicating health messages. However, the US public consumes substantially fewer whole-grain servings than recommended by US dietary guidance. Reasons given by consumers for not purchasing wholegrain foods include colour, price, softness, texture, moisture content and taste. Developing tastier value-added wholegrain foods along with simple coordinated messages from industry, the scientific community, public health experts and government will help consumers identify, purchase and consume more wholegrain products.
\end{abstract}

Whole grains: Health claims: FDA Modernization Act: Chronic disease: Dietary intake

The science of grains has evolved from the milling of flour for easy use in food preparation to the use of grains as a vehicle for nutrient delivery, and to the scientific understanding of grains as a tool for reducing risk of chronic disease. Modern flour milling was born in the mid 1800 s, allowing for the manufacture of refined grain flour for the masses. During the Second World War fortification of flour with B vitamins began as a way to correct multiple nutrient deficiencies, such as pellagra, prevalent among the US population. The 1960s highlighted grain foods as part of the basic four food groups that made up a healthful diet.

Epidemiological reviews and prospective studies of whole grain and its relationship to cancer, heart disease, diabetes, and overall death rates marked the 1990s. It was recognized that whole grains contain biologically-active compounds, beyond dietary fiber, such as antioxidants (phenolics, tocotrienols, phyto-oestrogens) that may elicit health benefits either individually, in combination and/or synergistically. Grains remain an integral part of the recommended diet for the US population, as evidenced by their prominent position on the Food Guide Pyramid (US Department of Agriculture, Department of Health and Human Services, 1992) and a specific recommendation in the latest dietary guidelines (US Department of Agriculture, Department of Health and Human Services, 2000). A whole grain health claim linking whole grain to reduced risk of heart disease and certain cancers was allowed by the Food and Drug Administration (FDA) in the summer of 1999 (Food and Drug Administration, 1999). The Healthy 
People 2010 report (US Department of Health and Human Services, 2000) designates that a specific number of wholegrain servings (three) be included in an individual's daily diet.

\section{Health claims in the USA}

With a shift towards disease prevention, the FDA established health claims linking specific foods or food components such as grains and/or grain components (soluble fibre and insoluble fibre) to specific diseases or conditions. Health claims on food labels were first permitted by the US Congress (1990) with the passage of the Nutrition Labeling and Education Act. These claims were designed to educate consumers and encourage consumption of healthful foods.

The first seven health claims finalized in January 1993 by the FDA were based on scientific consensus that included epidemiological, animal and clinical research studies to back up their association with disease prevention (Table 1). As part of the health claims regulation, the FDA established a process to petition for new health claims that addressed substance-disease relationships with an adequate scientific basis and that met specific regulatory requirements. Since the initial seven health claims were approved, six more have been approved through both the petitioning process and an alternative process established in 1997.

\section{Standard health claim petition procedures}

As they are now defined, health claims authorized by the FDA are messages that inform consumers about currently recognized links between nutrition and disease prevention

Table 1. Current status of health claims in the USA

Approved health claims
Soluble fibre and heart disease
Saturated fat, cholesterol and heart disease
Whole oats, psyllium and heart disease*
Fat and cancer
Fibre-containing grain products, fruits and vegetables and cancer
Fruits and vegetables and cancer
Ca and osteoporosis
Na and hypertension
Folic acid and neural-tube defects*
Sugar alcohols and dental caries*
Soyabean protein and heart disease*
Approved authoritative health claim statements
Whole grains and heart disease and cancer (first health claim
approved under the Food and Drug Administration Modernization
Act of $1997+$ )
K and high blood pressure
Health claims denied approval by the Food and Drug Administration
Dietary fibre and cancer (wheat bran and colon cancer)
Dietary fibre and cardiovascular disease
Antioxidant vitamins and cancer
Zn and immune function and the elderly
$n-3$ Fatty acids and CHD

*Approved following the Food and Drug Administration's ruling on health claims in 1993.

†Food and Drug Administration (1997).
(Marquart et al. 2001). While health claims can make a major contribution towards improving health, they can take $>1$ year to be approved, because of the scientific review, the publication of a proposed rule and the time for public comments, which are all mandated under the FDA's 1993 final food labelling rules for health claims as part of the Nutrition Labeling and Education Act (US Congress, 1990). The petitioner must submit a summary of the available scientific evidence to support the health claim being petitioned, an analysis of the evidence and a model health claim. Under these rules, the FDA is required to notify the petitioner within $15 \mathrm{~d}$ of receipt of the petition. Within $100 \mathrm{~d}$ after submission of the petition the FDA will notify the petitioner that the petition has either been filed or is denied. Within $90 \mathrm{~d}$ of the filing the FDA will then either deny the petition or inform the petitioner that a proposed regulation will be issued. The FDA will then publish the proposal in the Federal Register. Once the proposal has been published in the Federal Register, there is a public comment period of 60-120 d. The FDA then has an additional $180 \mathrm{~d}$ to modify, deny or issue a final regulation based on the comments the agency has received. The FDA has also taken the view that if the agency has already approved a health claim for a nutrient-disease relationship, then a prospective authoritative statement claim must not conflict with the previous claim. The entire process can take $\geq 1$ year.

The oat-heart disease health claim was the first, after the initial seven, to be authorized by the FDA using the new health claim petition process. The petition submitted by the Quaker Oats Company (Chicago, IL, USA; with strong support from the American Association of Cereal Chemists) in March 1995 focused on oatmeal and oat bran and addressed all key areas required by the health claim regulation. The scientific research used to support the health claim was extensive and focused on thirty-seven of fortyone clinical intervention trials which were submitted to the FDA by the company, as well as epidemiological and animal studies that also supported the oat-heart disease relationship. The FDA issued the proposed regulation for the oats health claim in January 1996. Based on public comments, the FDA broadened the health claim to include wholegrain oats and published the final regulation for the oats health claim in January 1997.

The following criteria are used by the FDA to evaluate the scientific evidence in support of proposed health claims. The evidence is weighted in descending order:

1. intervention studies: randomized controlled clinical trials, which are the 'Gold Standard' of scientific evidence;

2. observational studies: prospective and retrospective studies, including epidemiological, cohort, case-control, cross-sectional, time series, ecological and case report studies;

3. research synthesis studies: meta-analyses;

4. animal and in vitro studies: mechanistic.

Human studies should present data and adequately describe the study design and methods. For the investigation of cardiovascular disease, the studies should directly measure total blood cholesterol and other blood lipids 
related to CHD. The study population should be representative of the general US population and the published studies should be available in English.

\section{Food and Drug Administration Modernization Act health claim procedures}

In an effort to give consumers quicker access to healthpromoting information, the Food and Drug Administration Modernization Act of 1997 (Food and Drug Administration, 1997) included a provision designed to expedite the process for establishing the scientific basis for health claims. In 1998, the FDA issued a guidance document for industry that established criteria for determining the adequacy of health claims under the new procedure. The new law allows companies to notify the FDA of their intent to use a new health claim based on an already existing authoritative statement from one or more federal scientific bodies.

The FDA's role in the authoritative statement notification process includes a review by FDA scientific and policy staff. In addition, the FDA utilizes a deliberative process in which other relevant federal health agencies are contacted to review the scientific basis for the claim and the FDA must determine that the claim meets statutory requirements. (The FDA then has $120 \mathrm{~d}$ to allow or reject the claim.) The agency may also choose to issue an interim final rule, require a $120 \mathrm{~d}$ comment period and then determine if the statement is accepted and finalized or rejected. For the whole grains health claim, the FDA ultimately decided not to publish a notice that prohibited or modified the claim and accepted it as proposed. However, the new streamlined process does not relax the scientific standards for making a claim.

The current criteria state that the health claim must:

come from a federal scientific body (e.g. the National Institutes of Health, National Centers for Disease Control and Prevention, US Department of Agriculture or National Academy of Sciences);

be published by the scientific body and be currently in effect;

state a relationship between a nutrient and a disease or health-related condition;

not be a statement made individually by an employee of a federal scientific body, but rather reflect a consensus of the scientific body;

be based on the scientific body's deliberative review of the scientific evidence.

To facilitate a deliberative review, a channel of communication was set up between the federal scientific bodies and the FDA. Each scientific body was asked to provide an individual with sufficient authority to speak for the agency and assist the FDA in its efforts. These contacts formed the Liaison Group of Authoritative Statements, whose job it is to facilitate communication between the federal scientific bodies and the FDA.

While more than twelve petitions for health claims under this alternate streamlined procedure have been filed since the 1997 ruling, only two have been approved to date. The first was the authoritative statement for the connection between whole grains and reduced risk for some cancers and CHD. The second was an authoritative statement about the relationship between $\mathrm{K}$ intake and blood pressure submitted in 2000 by Tropicana (Bradenton, FL, USA), which reads, 'Diets containing foods that are good sources of potassium and low in sodium may reduce the risk of high blood pressure and stroke.'

General Mills Inc. (Minneapolis, MN, USA) submitted a notification to the FDA in March 1999, notifying the agency that it intended to make an authoritative statement health claim about the relationship between plant foods, and specifically wholegrain foods, and CHD and certain cancers. The statement in the Food and Nutrition Board Committee on Diet and Health report (Food and Nutrition Board, 1989) stated that: 'Diets high in plant foods - i.e., fruits, vegetables, legumes and whole-grain cereals - are associated with a lower occurrence of CHD and cancers of the lung, colon, esophagus, and stomach.' The filing of the notification was based on the fact that an expert panel of the National Research Council, a subdivision of the National Academy of Sciences, recognized these relationships and included them in the National Research Council's Food and Nutrition Board Committee on Diet and Health report (Food and Nutrition Board, 1989) on diet and disease relationships.

\section{Scientific documentation provided by General Mills in the Food and Drug Administration Modernization Act whole grains health claim notification}

There is a body of scientific research that provides compelling evidence that whole-grain consumption among the US population would have a marked impact on public health by reducing risk for some types of cancer and CHD. The review (Food and Drug Administration, 1999) provided support that confounding with other dietary and lifestyle factors did not explain the apparent protective effect of whole grains against cancer. The reduced risk for cancer was observed for higher whole-grain intake despite the type of dietary intake methodology used.

\section{CHD and whole grains}

There was moderately strong prospective epidemiological evidence to support an association between whole-grain intake and reduced risk for $\mathrm{CHD}$, as well as some strong clinical evidence to indicate that whole grains modify risk factors for CHD. Whole grains contain not only soluble and insoluble fibre, but other components that research suggests may help reduce risk for some types of cancer. The available evidence at the time of the notification to FDA clearly supported the relationship between a higher intake of whole grains and a reduced risk for CHD, including several large prospective epidemiological studies that controlled for demographic and other lifestyle variables. In addition, ecological and case-control studies, along with experimental and clinical interventions, showed a positive effect on CHD risk factors with higher intakes of wholegrain foods. When the petition was submitted to the FDA, fourteen studies were available to support the relationship between wholegrain foods and reduced risk of 
CHD and CHD risk factors (DeGroot et al. 1963; Fraser et al. 1981, 1992; Van Horn et al. 1986, 1988, 1991; Reynolds et al. 1989; Davidson et al. 1991; Ripsin et al. 1992; He et al. 1995; Pietinen et al. 1996; Appel et al. 1997; Jacobs et al. 1998b; Johnston et al. 1998). Ten more studies supported the relationship with wholegrain cereal fibre and risk of CHD and CHD risk factors (Knox, 1977; Morris et al. 1977; Anderson \& Ward, 1979; Karlstrom et al. 1984; Burr et al. 1989; Davidson et al. 1991; Ripsin et al. 1992; Rimm et al. 1996; Salmeron et al. 1997a,b). Only two studies do not support the relationship (Gramenzi et al. 1990; Judd \& Truswell, 1981).

The notification concluded that there was strong prospective epidemiological evidence supporting the association between intake of wholegrain foods and reduced risk for $\mathrm{CHD}$. Both de novo analyses conducted in the large prospective Iowa Women's Health Study (Jacobs et al. 1998b) and a Finnish study of rye food intake (Pietinen et al. 1996), suggested that wholegrain food intake reduced risk for CHD by about 25-30 \%. In another large prospective study cereal fibre was associated with reduced risk for myocardial infarction, with a $29 \%$ decrease in risk for each $10 \mathrm{~g}$ increase in cereal fibre intake (Rimm et al. 1996). The notification also pointed out the strong clinical evidence indicating that wholegrain foods are able to modify risk factors for CHD. For example, several randomized clinical trials demonstrated that wholegrain oat intake reduces blood cholesterol and one study found that the use of a variety of wholegrain foods was associated with a reduction of $90 \mathrm{mg} / \mathrm{l}$ in serum cholesterol (Fraser et al. 1981). Several studies also demonstrated an association between cereal fibre intake and reduced risk for diabetes, a major risk factor for CHD (Salmeron et al. 1997a,b). Wholegrain foods incorporated as part of a total healthful diet reduced both systolic and diastolic blood pressure (Appel et al. 1997). The notification concluded that, based on clinical prospective and experimental studies, the weight of evidence indicates consumption of wholegrain foods reduces risk for CHD.

\section{Cancer and whole grains}

An analysis of forty studies of twenty types of cancer published between 1984 and 1997, most of which were conducted in the USA and Europe, demonstrated that whole-grain consumption reduced risk for a variety of cancers (Jacobs et al. 1998a). Thirty-seven case-control studies show an association between whole-grain consumption and various types of cancers. Also, one ecological study, three review articles and a meta-analysis of forty case-control studies were included. Intake of wholegrain foods in these studies consistently reduced risk of neoplasms by 30-70 \% (oral cavity and pharynx, oesophagus, stomach, colon, rectum, liver, gallbladder, larynx, breast, ovary, prostate, bladder, kidney and nonHodgkin's lymphomas). Moreover, twenty-four studies investigating the connection between cereal and cereal fibre intake and colon cancer provided evidence supporting an association. Seven studies did not support the association (Food and Drug Administration, 1999).

\section{Overall, the data showed:}

a reduced risk for cancer for higher whole-grain intake despite the type of dietary intake methodology used; a strong consistency and moderately strong magnitude of association between whole-grain intake and reduced risk for cancer;

a moderately strong dose relationship between increased whole-grain intake and reduced risk for various cancers;

a persistent association between whole-grain intake and reduced risk of cancer, even when other confounding variables (e.g. diet, exercise, smoking, alcohol use) were controlled.

The notification concluded that regardless of how the evidence was analysed, either by cancer type or by type of wholegrain product consumed, there was compelling evidence in support of whole-grain consumption reducing the risk of some cancers.

\section{Potential biological mechanisms for whole grains}

The potential biological components that may explain why whole-grain consumption is associated with a reduced risk for CHD and some cancers, include fermentable carbohydrates, antioxidants, lignans and phytoestrogens, anti-nutrients, fat and associated substances (Slavin et al. 1997; Miller et al. 2000). This aspect is discussed in more detail by Slavin (2003) and Anderson (2003).

\section{Whole grain health claim final rule}

The whole grain health claim was permitted by the FDA in July 1999 (Food and Drug Administration, 1999). It is allowed on any low-fat product that contains $51 \%$ whole grains by weight per reference amount customarily consumed. The claim reads, 'Diets rich in whole grain foods and other plant foods and low in total fat, saturated fat, and cholesterol may reduce the risk of heart disease and some cancers.' Table 2 provides common breakfast cereals that meet the whole grain health claim.

\section{Implications of the whole grain health claim}

Approval of a whole grain health claim provides numerous benefits to consumers, government, industry and academia. From a public health standpoint, a whole grain claim can help governmental agencies and consumers to achieve dietary and health goals, and potentially contribute to overall reduction of chronic disease risk. Increased visibility and promotion of a whole grain claim offers consumers the opportunity to identify wholegrain foods, learn about the health benefits and explore ways of increasing consumption. Industry benefits from additional incentives to develop and promote wholegrain products, as well as from increased product demand. The health claim has highlighted the need for research on whole grains primarily from an academic perspective, with additional interest from the governmental scientific community. 
Table 2. Foods that meet whole grain health claim criteria

\begin{tabular}{|c|c|c|c|}
\hline Product & $\operatorname{RACC}(\mathrm{g})$ & Whole grain $(\mathrm{g})$ & Fibre $(\mathrm{g})$ \\
\hline \multicolumn{4}{|l|}{ Whole-grain cereals } \\
\hline \multicolumn{4}{|l|}{ General Mills* } \\
\hline Wheat Chex & 55 & 46 & 4.9 \\
\hline Crispy wheaties and raisins & 55 & 35 & $3 \cdot 8$ \\
\hline Oatmeal crisp with raisins & 55 & 33 & 3.3 \\
\hline Cheerios & 30 & 28 & $2 \cdot 8$ \\
\hline Wheaties & 30 & 27 & 3.4 \\
\hline Whole grain total & 30 & 26 & $3 \cdot 0$ \\
\hline Oatmeal crisp with apple & 55 & 21 & $2 \cdot 9$ \\
\hline Multigrain Cheerios plus & 30 & 18 & $1 \cdot 8$ \\
\hline \multicolumn{4}{|l|}{ Kellogg's $\dagger$} \\
\hline Healthy choice toasted brown sugar squares & 55 & 49 & $5 \cdot 3$ \\
\hline Raisin squares & 55 & 41 & $4 \cdot 4$ \\
\hline Frosted mini wheats bite size & 55 & 40 & $4 \cdot 3$ \\
\hline Frosted mini wheats & 55 & 40 & 4.3 \\
\hline Nutrigrain almond raisin & 55 & 39 & $4 \cdot 0$ \\
\hline Apple cinnamon squares & 55 & 37 & 4.0 \\
\hline Low-fat granola without raisins & 55 & 32 & $3 \cdot 2$ \\
\hline Healthy choice almond crunch with raisins & 55 & 32 & $3 \cdot 4$ \\
\hline Nutrigrain golden wheat & 30 & 30 & $3 \cdot 2$ \\
\hline \multicolumn{4}{|l|}{ Postł } \\
\hline Spoon size shredded wheat & 55 & 54 & $5 \cdot 8$ \\
\hline Shredded wheat & 55 & 54 & $5 \cdot 8$ \\
\hline Shredded wheat and bran & 55 & $54^{\|}$ & $5 \cdot 8$ \\
\hline Fruit and fibre peaches, raisins, almonds & 55 & $29^{\|}$ & $3 \cdot 1$ \\
\hline Grape Nuts flakes & 30 & 26 & $2 \cdot 8$ \\
\hline Grape Nuts & 55 & 41 & 4.4 \\
\hline Frosted shredded wheat bite size & 55 & 24 & $2 \cdot 6$ \\
\hline Raisin bran & 55 & $20^{\| \prime}$ & $2 \cdot 2$ \\
\hline \multicolumn{4}{|l|}{ Quaker§ } \\
\hline Shredded Wheat & 55 & 54 & $5 \cdot 8$ \\
\hline Oatmeal squares & 55 & 44 & $4 \cdot 3$ \\
\hline Oatmeal regular (Hot) & 40 & 40 & 4.0 \\
\hline Toasted oatmeal honey nut & 55 & 36 & $3 \cdot 6$ \\
\hline Natural low-fat granola with raisins & 55 & 33 & $3 \cdot 6$ \\
\hline Life & 30 & 18 & $1 \cdot 8$ \\
\hline Cinnamon Life & 30 & 18 & 1.9 \\
\hline \multicolumn{4}{|l|}{ Malt-O-Meal* } \\
\hline Toasty-O’s & 30 & 28 & $2 \cdot 8$ \\
\hline \multicolumn{4}{|l|}{ Breads, Rolls } \\
\hline Whole wheat bread & 50 & 28 & $3 \cdot 0$ \\
\hline Whole wheat pitta & 50 & 34 & $3 \cdot 7$ \\
\hline Whole wheat English muffin & 55 & 33 & 3.5 \\
\hline Whole wheat bagel & 55 & 31 & $3 \cdot 3$ \\
\hline Whole wheat roll & 50 & 29 & $3 \cdot 1$ \\
\hline Whole wheat biscuit & 55 & 29 & $3 \cdot 1$ \\
\hline Snacks/crackers & 30 & 27 & $2 \cdot 9$ \\
\hline Tortilla chips, baked & 30 & 23 & $2 \cdot 2$ \\
\hline Popcorn, low-fat (popped) & 30 & 27 & 4.3 \\
\hline \multicolumn{4}{|l|}{ Grains (pasta, rice, noodles) } \\
\hline Whole wheat tortilla & 55 & 33 & 3.5 \\
\hline Whole wheat macaroni, prepared (55 g dry) & 140 & 32 & 3.4 \\
\hline Whole wheat spaghetti, prepared (55 g dry) & 140 & 32 & 3.4 \\
\hline Whole wheat noodles, prepared (55 g dry) & 140 & 28 & $3 \cdot 0$ \\
\hline Wild rice, prepared ( $45 \mathrm{~g}$ dry) & 140 & 34 & 2.5 \\
\hline Bulgur, prepared ( 45 g dry) & 140 & 33 & $>3 \cdot 0$ \\
\hline
\end{tabular}

RACC, reference amount customarily consumed,

*Minneapolis, MN, USA.

†Battle Creek, MI, USA

łFoods-Post, Chicago, IO, USA.

§Chicago, IL, USA.

"May be overestimated, as they include bran as well as whole grain 


\section{Increasing whole-grain consumption}

The American public consumes substantially fewer grain and whole-grain servings than are recommended by US dietary guidance. As such, a coordinated multi-faceted action plan needs to be developed in order to reach the consumer with wholegrain products and messages. The National Cancer Institute's '5-a-day' programme exemplifies this type of action plan. The '5-a-day' campaign has enjoyed tremendous success in raising consumer awareness, encouraging and supporting research, and partnering with industry to achieve a common goal of increasing fruit and vegetable consumption. The Dietary Guidelines for Americans (US Department of Agriculture, Department of Health and Human Services, 2000), Food Guide Pyramid (US Department of Agriculture, Department of Health and Human Services, 1992), Healthy People 2010 (US Department of Health and Human Services, 2000) and the American Heart Association (Krauss et al. 2001) similarly represent multidisciplinary nutrition and health campaigns. Grain advocates can follow these models in expanding and strengthening existing alliances, and in forming a consortium of advocates from academia, government, public and private agencies, and industry to develop tactics to address key grain issues (Jones et al. 2002a).

\section{Highlights of 'Grains for the health of it' Symposium}

In September 2001 experts from industry, academia, public health and trade associations gathered to address the challenge of moving forward in promoting a wholegrain foods message. Participants included biological and behavioural scientists, millers, processors, food scientists, marketers, bakers and educators, who were unified in a 'call-to-action' to help the US population increase whole grain consumption (Jones et al. 2002b; Marquart et al. 2002; Wheat Foods Council, 2002a). Topics included future priorities for wholegrain research, implementation of communication strategy and funding.

The following summarizes future priorities and key messages for whole grains derived from this meeting.

\section{Additional epidemiological and clinical research is necessary to understand the relationship between whole-grain intake and disease prevention}

Research examining whole-grain intake and diabetes, heart disease, cancer and weight management may potentially have an important impact on the health of the US population. However, further studies are needed to elucidate the potential protective roles of grains and whole grains, and their interrelationship with other foods. Examining the role of whole-grain intake on satiety and body-weight regulation is of particular interest as a preventative measure in these diseases. Metabolic studies will further our understanding of the effects of grains on risk factors such as glucose and insulin response, blood lipids, clotting factors and inflammation. In terms of cancer research valid biological markers for disease (as opposed to cancer end points) are necessary in order to elucidate the role of dietary factors such as whole grains in the aetiology of this disease.
Dietary intake research is an important component in population studies to determine whole-grain intake and identify differences in consumption patterns among populations. This data will also serve as a quantitative means to measure the success of programmes designed to increase whole-grain intake. A clear definition of a 'serving' of whole grain needs to be clarified for research and consumer purposes.

\section{Food industry support is crucial}

Learning how processing affects the bioavailability of nutrients and phytochemicals will further the potential development of grain products that offer maximal health benefits. Thus, functional components of whole grains might be enhanced through hybridization, milling, processing and genomics. Research and development on the ideal taste, colour and texture profile of wholegrain products is much needed from a government, academic and industry perspective.

Limited availability may be a contributing factor in low whole-grain consumption; industry experts estimate that only $5-10 \%$ of retail grain products are derived from whole grain, and that the primary products providing whole grain are breads, breakfast cereals and crackers (Kantor et al. 2001). Of the top ten largest-selling baked goods in supermarkets, only one is wholewheat and none is wholegrain (Wheat Foods Council, 2002a, 2002b). Dietary and consumer surveys suggest the availability of wholegrain products are more limited in food service settings than at home. Continuing Survey of Food Intakes by Individuals (US Department of Agriculture, 2000) data from 1994 to 1996 showed that two-thirds of total grain servings were from 'at home' sources, while $<15 \%$ of whole-grain servings were from 'away from home' sources. Restaurants provided $20 \%$ of the total food energy but $<6 \%$ of the total whole-grain servings (Kantor et al. 2001). Since the total food dollars spent on food eaten away from home is increasing (Lin et al. 1999), the availability of wholegrain products in food service facilities becomes increasingly important.

This situation calls for increased availability of wholegrain foods served at home and in food service establishments. Creative thinkers in the industry are vital for the development of new products that will be embraced by consumers of all ages. The encouraging news is that growth trends in consumption of wholegrain bread have been observed. Wholegrain bread consumption tends to increase with age; the baby boomer generation is getting older, suggesting that consumption will continue to rise.

Industry will only produce more better-tasting higherquality wholegrain products when consumers drive the market demand. Currently, whole grains cost more than refined-grain products due to product development costs, low product volume and inexperience in marketing and developing whole grains. Reasons given by consumers for not purchasing wholegrain bread included the colour, price, softness, texture, moisture content and taste (Wheat Foods Council, 2002b). Industry has begun to address some of these issues by developing whole-grain products lighter in colour from white wheat flour. A coordinated education programme among manufacturers, retailers, and restaurants 
could drive innovation and increase consumer demand for wholegrain products. Continued innovation in the food industry will offer consumers a wider array of tasty wholegrain products.

\section{Understand consumers, lifestyles and needs}

Develop a consumer-friendly whole grain definition and identifier. Most whole grains are milled, processed and packaged, making it difficult for consumers, health professionals, scientists and even food service managers to identify wholegrain products (Warber et al. 1996; Adams, 2000). There is a need to develop a 'consumer-friendly whole grain definition so that consumers can easily identify what is a wholegrain product. In addition, a universal onpackage whole grain identifier would be useful, such as a seal, logo or insignia to readily signify wholegrain products. It cannot be hoped to successfully educate, market and increase whole-grain consumption until consumers can identify wholegrain foods.

Develop whole grain message points. The nutrition community needs a clear concise message in order to successfully communicate with the consumer. Simple coordinated messages from industry, the scientific community, public health experts and government will help consumers identify and purchase wholegrain products.

Develop and support messages that position wholegrain foods as essential to healthful eating. Consumers need to be encouraged to think about their total diet, while emphasizing the importance of wholegrain foods. The focus should be on positive and consistent messages that encourage improvement, not perfection. Small dietary modifications with long-term realistic expectations may have the most permanent results. Switching to whole grains is easier than many dietary changes, because it does not require a change in eating style. Consumers do not need to give up their favourite foods from the grain group. Examples of messages include: try a wholegrain cereal for breakfast or even dinner when you are in a hurry; make a sandwich with one slice of wholewheat bread and one slice of white for taste and nutrition; add bulgur to your chilli or spaghetti sauce for that extra nutrition. These and other examples demonstrate to consumers how easy it is to integrate whole grains into their lifestyle. It is unrealistic, and not necessary, for consumers to switch all their grain food servings to whole grain. In fact, just three daily servings of whole grain are recommended, of a total of six to eleven.

Train health professionals as spokespersons to convey whole grain findings and messages to the media and to consumers. The media is an important source of health and nutrition information for consumers. A strong media campaign involving physicians, dietitians and other nutrition experts can be a driving force in educating the consumer about the benefits of whole grain. These efforts may eventually spark the food industry to develop and market more higher-quality wholegrain products.

Target youth through early intervention and through alliances with school food service Children are a primary influence on household food purchases. However, children often reject the taste and texture of wholegrain products, and are major influencers of family bread purchases, especially white bread (Wheat Foods Council, 2002a). A whole grain consortium could form a partnership with the school food service and administration to develop health promotion programmes with the National School Food Service Association. Over twenty-seven million students participate in school lunch on a daily basis. To encourage children to eat more whole grains school breakfast and lunch programmes could gradually introduce wholegrain flour (from 10-50\% of the total flour content by weight) into traditional refined-grain products such as pizza, bread and hamburger buns. This analogy is similar to the gradual adaptation from whole milk down to skim milk, with 1 and $2 \%$ milk fat acting as stepping-stones in the transition process. This gradual incorporation of wholegrain flour into partial wholegrain foods may provide an opportunity to increase whole-grain consumption within the school food service setting. New recipes for partial wholegrain dishes could be developed and disseminated to schools around the country. A legislative agenda focused on increased funding for child nutrition through Women, Infants and Children, Head Start and Cooperative Extension (programmes, either specifically or in part, to improve the nutrition of US children) could help reach consumers at an early age and guide them towards greater whole-grain intake as a positive lifelong practice.

\section{Policy support for whole grains and health}

Maintain grains at the base of the Food Guide Pyramid The general grain message should include a goal of three daily servings of whole grains, as a realistic and attainable target. It is important to work together to position grains at the base of the Food Guide Pyramid as the foundation of a healthful diet and to reinforce with government agencies the continued emphasis on whole grains in future editions of the Dietary Guidelines and the Healthy People reports.

\section{Regulatory and health claim support}

Consideration should be given to expand and modify the health claim so that it can be more readily used by products that are higher in water than cereals (e.g. breads, pizza crusts, etc.) or by foods that fail to meet the $1.7 \mathrm{~g}$ dietary fibre per serving (such as brown rice). Claims that reward some level of whole grain in a product may be helpful in encouraging greater overall consumption. An example might include a 'Good' or 'Excellent' source of whole grain. Regular intake of products containing 10-25\% whole grain by weight may positively impact on consumption on a population-wide basis.

\section{Secure funding for whole grains research}

Collaborative efforts from a wide variety of disciplines such as genomics, medicine, nutrition, agriculture and social sciences from both a national and international scope are needed to better understand the relationship between whole grains and health from a biological, behavioural and dietary intake perspective. How can funding be secured for whole grain research from a whole foods perspective along 
with contributions from individual efficacious components? Research partnerships with Governmental agencies (National Institutes of Health, US Department of Agriculture, Centers for Disease Control) and non-profit associations (such as the American Heart Association and American Cancer Society) can enable larger-scale studies on the effects of grains on specific diseases.

Substantial government dollars were designated to examine the health benefits of soyabean and fruits and vegetables. Non-profit agencies followed up with additional funding for specific diseases. Industry also contributed considerable dollars for research, promotion and health claims for soyabean and heart disease, and $\mathrm{K}$ and blood pressure. This financial support is a major reason why these foods have received considerable attention from scientists, health professionals and the media.

Funding for consumer research will help in probing deeper into consumer understanding and attitudes about whole grains and healthful eating. Focus groups and survey research will provide insight into the following issues: how can whole grains be effectively explained to consumers; how can consumers be helped to identify and purchase wholegrain products; what is a compelling message to encourage consumers to eat whole grains. Development of a consumer-friendly whole grain definition, an effective wholegrain product identifier (logo, seal, insignia) and consumer-friendly whole grain messages are absolutely essential before whole grain behavioural interventions can be conducted.

\section{Whole grain: the recent past and the next 10 years}

The recent past has been quite exciting in terms of strides made in the area of whole-grain research, policy and regulatory issues, and dietary intake. Considerable research has been conducted in order to demonstrate that wholegrain foods as commonly consumed in the USA and Europe reduce the risk for heart disease, certain cancers and, most recently, diabetes. Much has been done to establish US policy and regulatory guidelines regarding whole grains and health. The FDA Modernization Act health claim for whole grain was allowed by the FDA in July 1999 (Food and Drug Administration, 1999), while the 2000 Dietary Guidelines for Americans (US Department of Agriculture, Department of Health and Human Services, 2002) established a separate guideline for grains and provided particular emphasis on wholegrain food consumption. The 'Healthy People Goals and Objectives for the Nation' (US Department of Health and Human Services, 2000) established a goal of at least three daily whole-grain servings for $50 \%$ of the US population by 2010 . Despite these strides, dietary intake data suggests that $40 \%$ of the US population never eat a wholegrain product and the average consumption is about one whole-grain serving, well below the recommended serving of three whole grains daily.

Given that the efforts to increase knowledge about whole grains and enhance dietary intake are in their infancy, it is necessary to move forward with focus groups and behavioural interventions to learn about the various tools, messages and campaigns that might be used in the strategy to increase whole-grain consumption. In addition, focused biological research to ascertain specific mechanisms that might be responsible for the protective effects of whole grains is essential to further solidify a scientific foundation from which to move forward. The whole grain strategy will need to be easy to implement, realistic and simple for consumers. There is much work to be done, involving a coordinated effort by many disciplines, if the 'Healthy People 2010' dietary goal of consuming three whole grains on a daily basis is to be met.

\section{References}

Adams JF (2000) Dietary intake of whole grain vs. recommendations. Cereal Foods World 45, 75-78.

Anderson JW (2003) Whole grains protect against atherosclerotic cardiovascular disease. Proceedings of the Nutrition Society $\mathbf{6 2}$, 000-000.

Anderson JW \& Ward K (1979) High-carbohydrate, high-fiber diets for insulin-treated men with diabetes mellitus. American Journal of Clinical Nutrition 32, 2312-2321.

Appel LJ, Moore TJ, Obarzanek E, Vollmer W, Svetkey L, Sacks F, Bray G, Vogt T, Cutler J, Windhauser M, Lin P \& Karanja N (1997) A clinical trial of the effects of dietary patterns on blood pressure. New England Journal of Medicine 336, 1117-1124.

Burr ML, Fehily AM, Gilbert JF, Rogers S, Holliday RM, Sweetman PM, Elwood PC \& Deadman NM (1989) Effects of changes in fat, fish, and fiber intakes on death and myocardial infarction: diet and reinfarction (DART). Lancet ii, 757-761.

Davidson MH, Dugan LD, Burns JH, Bova J, Story K \& Drennan KB (1991) The hypocholesterolemic effects of beta-glucan in oatmeal and oat bran - a dose-controlled study. Journal of the American Medical Association 265, 1833-1839.

DeGroot AP, Luyken R \& Pikaar NA (1963) Cholesterol-lowering effect of rolled oats. Lancet ii, 203.

Food and Drug Administration (1997) Food and Drug Administration Modernization Act. http://www.fda.gov/cder/guidance/ 105-115.htm\#SEC.\%20303

Food and Drug Administration (1999) Whole-Grain Foods Authoritative Statement Claim Notification. Docket 99P-2209. http://www.fda.gov/ohrms/dockets/dailys/070899/070899.htm

Food and Nutrition Board (1989) FNB Committee on Diet and Health: Implications for Reducing Chronic Disease Risk. Washington, DC: National Research Council.

Fraser GE, Jacobs DR, Anderson JT, Foster N, Palta M \& Blackburn H (1981) The effect of various vegetable supplements on serum cholesterol. American Journal of Clinical Nutrition 34, 1272-1277.

Fraser GE, Sabate J, Beeson WL \& Strahan TM (1992) A possible protective effect of nut consumption on risk of coronary heart disease: The Adventist Health Study. Archives of Internal Medicine 152, 1416-1424.

Gramenzi A, Gentile A, Fasoli M, Negri E, Parazzine F \& LaVecchia C (1990) Association between certain foods and risk of acute myocardial infarction in women. British Medicine Journal 300, 771-773.

He J, Klag MJ, Whelton PK, Mo JP, Chen JY, Qian MC, Mo PS \& He GQ (1995) Oats and buckwheat intakes and cardiovascular disease risk factors in an ethnic minority of China. American Journal of Clinical Nutrition 61, 366-372.

Jacobs DR, Marquart L, Slavin J \& Kushi LH (1998a) Whole grain intake and cancer: An expanded review and meta-analysis. Nutrition and Cancer 30, 85-96.

Jacobs DR Jr, Meyer KA, Kushi LH \& Folsom AR (1998b) Whole grain intake may reduced the risk of ischemic heart disease death 
in postmenopausal women: The Iowa Women's Health Study. American Journal of Clinical Nutrition 68, 248-257.

Johnston L, Reynolds HR, Patz M, Hunninghake DB, Schultz K \& Westereng B (1998) Cholesterol-lowering benefits of a whole grain oat ready-to-eat cereal. Nutrition Clinical Care 1, 6-12.

Jones JM, Reicks M, Adams J, Fulcher RG, Weaver G, Kanter M \& Marquart L (2002a) The importance of promoting a whole grain foods message. Journal of the American College of Nutrition 21, 293-297.

Jones JM, Reicks M, Fulcher RG, Marquart L, Adams J, Weaver G \& Kanter M (2002b) Taking action to move forward with the message about whole grains. In Whole Grains in Health and Disease, pp. 359-369 [L Marquart, J Slavin and RG Fulcher, editors]. St Paul, MN: American Association of Cereal Chemists.

Judd PA \& Truswell AS (1981) The effect of rolled oats on blood lipids and fecal steroid excretion in man. American Journal of Clinical Nutrition 34, 2061-2067.

Kantor LS, Variyam JN, Allshouse JE, Putnam JJ \& Lin BH (2001) Choose a variety of grains daily, especially whole grains: A challenge for consumers. Journal of Nutrition 131, 473S-486S.

Karlstrom B, Vessby B, Asp NG, Boberg M, Gustafsson IB, Lithell H \& Werner I (1984) Effects of an increased content of cereal fibre in the diet of type 2 (non-insulin-dependent) diabetic patients. Diabetologia 26, 272-277.

Knox EG (1977) Foods and disease. British Journal of Preventive Social Medicine 31, 1307-1314.

Krauss R, Eckel R, Howard B, Daniels S, Kris-Etherton P, Lichtenstein A, Wylie-Rosett J \& Bazzarre T (2001) American Heart Association Dietary Guidelines. Revision 2000: A statement for healthcare professionals from the Nutrition Committee of the American Heart Association. Circulation 102, 2284.

Lin B-H, Frazao E \& Guthrie J (1999) Away-From-Home Foods Increasingly Important to Quality of American Diet. Agriculture Information Bulletin no. 749. Washington, DC: US Government Printing Office.

Marquart L, Slavin J \& Fulcher RG (editors) (2002) Future issues and directions for grains and health: the next ten years. In Whole Grains in Health and Disease, pp. 371-374. St Paul, MN: American Association of Cereal Chemists.

Marquart L, Wiemer K \& Jacob B (2001) Health claims: Solid science and effective marketing. Nutrition Today 36, 1-6.

Miller H, Kanter M, Marquart L, Prakash A \& Rigelhof F (2000) Antioxidant content of whole grain breakfast cereals, fruits and vegetables. Journal of the American College of Nutrition 19, 312S-319S

Morris J, Marr J \& Clayton D (1977) Diet and heart: A postscript. British Medical Journal 2, 1307-1314.

Pietinen P, Rimm EB, Korhonen P, Hartman AM, Willett WC, Albanes D \& Virtamo J (1996) Intake of dietary fiber and risk of coronary heart disease in a cohort of Finnish men. The Alpha-Tocopherol, Beta-Carotene Cancer Prevention Study. Circulation 94, 2720-2727.

Reynolds H, Lindeke E \& Hunninghake D (1989) Effect of oat bran on serum lipids. Journal of the American Dietetic Association 89, A112.

Rimm EB, Ascherio A, Giovannucci E, Spiegelman D, Stampfer MJ \& Willett WC (1996) Vegetable, fruit and cereal fiber intake and risk of coronary heart disease among men. Journal of the American Medical Association 275, 447-451.
Ripsin CM, Keenan JM, Jacobs DR, Elmer PJ, Welch RR, Van Horn L, Lieu K, Turnbull WH, Thye FW, Kestin M, Hegsted M, Davidson DM, Davidson MH, Dugan LD, Demark-Wahnefried WQ \& Belin S (1992) Oat products and lipid lowering - a metaanalysis. Journal of the American Medical Association 267, 447-451.

Salmeron J, Ascherio A, Rimm E, Colditz G, Spiegelman D, Jenkins D, Stampfer M, Wing A \& Willett W (1997a) Dietary fiber, glycemic load, and risk of NIDDM in men. Diabetes Care 20, 545-550.

Salmeron J, Manson J, Colditz G, Wing A \& Willett W (1997b) Dietary fiber, glycemic load, and risk of non-insulin-dependent diabetes mellitus in women. Journal of the American Medical Association 277, 472-477.

Slavin J (2003) Why whole grains are protective: biological mechanisms. Proceedings of the Nutrition Society 62, 000-000.

Slavin J, Jacobs D \& Marquart L (1997) Whole grain consumption and chronic diseases: Protective mechanisms. Nutrition and Cancer 27, 14-21.

US Congress (1990) Nutrition Labeling and Education Act. Washington, DC: US Government Printing Office.

US Department of Agriculture, Department of Health and Human Services (1992) The Food Guide Pyramid. Home and Garden Bulletin no. 252. Washington, DC: US Government Printing Office.

US Department of Agriculture, Department of Health and Human Services (2000) Dietary Guidelines for Americans. Washington, DC: US Government Printing Office.

US Department of Health and Human Services (2000) Healthy People 2010, conference ed. Washington, DC: US Government Printing Office.

Van Horn L, Emidy LA, Lieu K, Liao Y, Ballew C, King J \& Stamler J (1988) Serum lipid response to a fat-modified oatmeal-enhanced diet. Preventative Medicine 17, 377-386.

Van Horn L, Liu K, Parker D, Emidy L, Liao Y, Pan WH, Giumetti D, Hewitt J \& Stamler J (1986) Serum lipid response to oat product intake with a response to oat product intake with a fat-modified diet. Journal of the American Dietetic Association 86, 759-764.

Van Horn L, Moag-Stahlberg A, Liu KA, Ballew C, Ruth K, Hughes R \& Stamler J (1991) Effects on serum lipids of adding instant oats to usual American diets. American Journal of Public Health 81, 183-188.

Warber JP, Haddad EH, Hodgkin GE \& Lee JW (1996) Foodservice specialists exhibit lack of knowledge in identifying grain products. Journal of the American Dietetic Association 96, 796-798.

Wheat Foods Council (2002a) Grains for the Health of It: Increasing Grains and Whole Grain Consumption as a Strategy for Health (Proceedings). http://wheatfoods.org/symposium_ proceedings.html

Wheat Foods Council (2002b) Grains for the Health of It: Increasing Grains and Whole Grain Consumption as a Strategy for Health (Proceedings). http://wheatfoods.org/pdfs/grains_ for_the_health_of_it/pt3_plenary_session.pdf

Wiemer K (2002) Whole-grains health claims: supporting scientific evidence and the FDA Modernization Act process. In Whole Grains in Health and Disease, pp. 327-340 [L Marquart, J Slavin and RG Fulcher, editors]. St Paul, MN: American Association of Cereal Chemists. 